\title{
SOME INEQUALITIES FOR GRAPHS DERIVABLE FROM HÖLDER'S INEQUALITY
}

\author{
D. G. HOFFMAN AND P. D. JOHNSON JR. *
}

\begin{abstract}
Inequalities are derived as advertised in the title. For instance, it is shown that for a finite simple graph $G, 4 m \leqslant n\left(J_{1}+t_{1}\right)$, where $m$ is the number of edges of $G, n$ is the number of vertices, $J_{1}$ is the average (over the edges) of the sizes of the "joint neighborhoods" of adjacent vertices, and $t_{1}$ is the average (over the edges) of the numbers of triangles in which the edges appear; with equality if and only if $G$ is regular.
\end{abstract}

Mathematics subject classification (2000): 05C30.

Key words and phrases: Graph, simple graph, multigraph, regular, degree, Hölder's inequality.

\section{REFERENCES}

[1] C. E. EdwaRds, P. D. Johnson JR. AND Zs. TuZA, Another extremal property of some Turán graphs, European Journal of Combinatorics 8 (1987), 27-28.

[2] D. G. HofFman AND P. D. JohnSON JR., An extremal family of strongly regular graphs, Congressus Numerantium 78 (1990), 119-122.

[3] P. D. JOHNSON JR. AND R. L. PERRY, Inequalities relating degrees of adjacent vertices to the average degree, European J. Comb. 7 (1986), 237-241.

[4] P. D. JOHNSON JR. AND K. J. ROBLEE, More extremal graphs for a maximal-joint-neighborhood average-triangles-per-edge inequality, Congressus Numerantium 140 (1999), 87-95.

[5] D. B. WeSt, Introduction to Graph Theory, Prentice-Hall, 1996. 